\title{
Mineral Profiling and Phytochemical Assessment of Lepidium sativum Seeds from Tropical Western India
}

\author{
Pushpendra Koli ${ }^{1 *}$, Jitendra Kumar ${ }^{2,4}$, Braj B. Singh ${ }^{3}$ and Satyanshu. Kumar ${ }^{2}$ \\ ${ }^{1}$ ICAR-Indian Grassland and Fodder Research Institute, Jhansi-284003, UP \\ ${ }^{2}$ ICAR-Directorate of Medicinal and Aromatic Plants Research, Anand-387310, Gujarat \\ ${ }^{3}$ ICAR-Indian Agricultural Research Institute, New Delhi-110012 \\ ${ }^{4}$ Institute of Pesticide Formulation Technology, Gurugram, Haryana
}

*Corresponding autho

\begin{tabular}{|l|}
\hline Ke y w o r d s \\
Lepidium sativum, \\
Livestock feed, \\
Glucosinolate, \\
DPPH, AAS, \\
Mineral profiling \\
\hline Article Info \\
\hline $\begin{array}{l}\text { Accepted: } \\
\text { 20 July } 2018 \\
\text { Available Online: } \\
\text { 10 August } 2018\end{array}$ \\
\hline
\end{tabular}

A B S T R A C T

From the time unknown, Lepidium sativum, an edible herb, has been recognized as an important medicinal plant. It has also been known to show good galactogogue property. In the present study, mineral profiling and phytochemical analysis of Lepidium seeds have been presented with the aim to recognize its importance as livestock feed. Mineral profiling was carried out with Flame Photometer and Atomic Absorption Spectrophotometer (AAS) and results showed the occurrence of K (11.9 g/kg), Na (1.23 $\mathrm{g} / \mathrm{kg}), \mathrm{Ca}(2.91 \mathrm{~g} / \mathrm{kg}), \mathrm{Mg}(3.15 \mathrm{~g} / \mathrm{kg}), \mathrm{Zn}(0.045 \mathrm{~g} / \mathrm{kg}), \mathrm{Cu}(0.006 \mathrm{~g} / \mathrm{kg}), \mathrm{Fe}(0.072 \mathrm{~g} / \mathrm{kg})$ and $\mathrm{Mn}(0.031 \mathrm{~g} / \mathrm{kg})$. For phytochemical assessment, oil was extracted from the crushed seed powder using soxhlet extraction method and $25.36 \%$ yield was recorded. Further, the phenolic extraction through refluxing of defatted seed powder was done to determine other biochemical contents and yield of phenolic extract was obtained around $20.23 \%$. Total phenolic content determined through Folin test was $8.53 \mathrm{mg} / \mathrm{g}$ of seeds. Crude fibers in seed meal were also estimated to be $23 \%$ in yield. Glucosinolate content was found 89 $\mu$ moles $/ \mathrm{g}$ of seeds. Total flavonoids content was found to be $3.89 \mathrm{mg} / \mathrm{g}$ of seeds in phenolic extracts. DPPH (2,2- Diphenyl-1-picryl-hydrazine) free radical scavenging method was used to measure antioxidant activity and $\mathrm{IC}_{50}$ was found to be $21 \mathrm{ppm}$ for methanolic extract. The present studies have revealed that L. sativum seeds have important mineral nutrients, fibers and other essential biochemical constituents and hence considered useful as animal feed and its health.

\section{Introduction}

In recent years, the use of crude medicinal plants assures health promoting effects in humans and animals due to its useful and effective bioactive principles without any side effects. As a great physician, Hippocrates
(460-370 B.C.) quoted "Let food be thy medicine and medicine be thy food". Also, same thing was reported in a book, Drug may not be the only cure for disease; food is our best medicine (Bieler, 2010). Therefore, medicinal plants are still a major area of research for their beneficial uses (Bauri et al., 
2015). The traditional knowledge on plant herbs were reported in animal health cure, reduces infections in udder such as Mastitis, udder oedema etc. by increasing the blood circulation in the udder and therapy use for livestock among poor farmers also well described (Gaur et al., 2010; Patil, 2009; Mirzaei, 2012; Viegi et al., 2003). Many of the medicinal herbs do not show the residual effects. Azadirachta indica, Zizyphus vulgaris, Ocimum gratissimum and Atlanta monophylla have the strong antibacterial activity, whereas Ocimum plant has strong antioxidant, anticarcinogenic, antifungal, analgesic and antipyretic properties (Tippu et al., 2006). Phytogenic feed additives comprise a wide variety of herbs, spices, and essential oils which improve the performance of agricultural livestock (Mirzaei et al., 2012).

More recently, Lepidium sp. has been reported to possess nutritive and medicinal properties (Agarwal et al., 2013). In addition to this, Lepidium has also been known to show good galactogogue property (Bnouham, 2010). Asilo (Lepidium sativum) has been considered as important medicinal plant since Vedic era (Agarwal et al., 2013). It is an edible herb and belongs to brassicaceae family. The species is a native of Ethopia and later introduced to Europe and Asia. Plant is of about 45-60 cm tall and leaves are entire or variously lobbed or pinnatisect (Sharma et al., 2011). Because of pungent taste its seedlings are used as salads in many parts of the world (Diwakar et al., 2010). L. sativum is a fast growing annual herb, in India it is commonly known as Asalio or Chandrasoor. Whole fruits or seeds are used, fresh or dried, as a seasoning with a peppery flavor. Boiled seeds are consumed in drinks by Arabs, either ground in honey or as an infusion in hot milk. The seed oil can be used for illumination and soap making. In Ethiopia the seed and its oil are primarily used medicinally, but also as condiment and in baking. But in India it is mainly grown for seed purpose. Asilo Seeds are bitter, thermogenic, depurative, rubefacient, galactogogue, tonic, aphrodisiac, ophthalmic, antiscorbutic, antihistaminic and diuretic. In the treatment of asthma, coughs with expectoration, poultices for sprains, leprosy, skin disease, dysentery, diarrhoea, splenomegaly, dyspepsia, lumbago, leucorrhoea, scurvy and seminal weakness it is very helpful (Kirthikar, 1952; Bnouham, 2010). This plant is having lactation properties which enhance the quantity and quality of milk in cattles. Therefore, based on above findings we have focused our study of $L$. sativum and its chemical properties which would be useful in exemplifying it as an animal feed.

\section{Materials and Methods}

\section{Plant material and extract preparation}

Lepidium sativum seeds were collected after harvesting the crop from research farm of ICAR- Directorate of Medicinal and Aromatic Plants Research, Anand, Gujarat. Seeds were shadow air dried. Further, seeds were powdered using an electric grinder and stored in plastic containers.

Oil from the seeds was extracted by Soxhlet extraction methods. For oil extraction (refluxing), $100 \mathrm{~g}$ of seed powdered was mixed with $200 \mathrm{ml}$ of hexane in a round bottom flask and refluxed for about 7 hours at $100^{\circ} \mathrm{C}$. After completion of refluxing content has been filtered through vacuum filtration and filtrate was concentrated by rotatory evaporator. Similarly, $20 \mathrm{~g}$ of defatted seed powder was mixed with methanol and water (8:2) of 200 $\mathrm{ml}$ volume of solvent in $500 \mathrm{ml}$ round bottom flasks and refluxed for $5 \mathrm{~h}$ to get total phenolics content. Liquid extracts obtained were separated from the solid residue by vacuum filtration, concentrated using a rotary evaporator.

All analytical grade reagents and chemicals were used during the experiment. Cellulose, 
Gallic acid, Quercetin, DPPH (2,2- Diphenyl1-picryl-hydrazine) and other reagents were purchased from Sigma-Aldrich.

\section{Mineral profiling}

Different minerals have been analyzed in seed extract of $L$. sativum with help of Flame Photometer and Atomic Absorption Spectrophotometer (AAS). Acid digestion technique was used to estimate these minerals. Nitric acid was used in microwave digestion and after oxidizing the samples their aliquots were used to estimate potassium $(\mathrm{K})$ and sodium (Na) by flame photometry (Flame Photometer Model-EEL). Other minerals like calcium $(\mathrm{Ca})$, magnesium $(\mathrm{Mg})$, zinc $(\mathrm{Zn})$, copper $(\mathrm{Cu})$, iron $(\mathrm{Fe})$ and manganese $(\mathrm{Mn})$ were determined atomic absorption spectrophotometry (AAS, Perkin-Elmer Model 5000) as described by Gençcelep et al., 2009.

Calculations were done by using following formula:

Metal $\mathrm{g} / \mathrm{kg}=($ Concentration of metal in $\mathrm{g} / \mathrm{kg} x$ volume made)/ weight of sample

The concentration of metal was detected in $\mathrm{g} / \mathrm{kg}$.

\section{Determination of total phenolics in extracts}

Folin-Ciocalteau method was used to estimate total phenolic contents in the extracts by UVVIS spectrometer (Singleton et al., 1999). Dried extracts were reconstituted in distilled water $(1 \mathrm{mg} / \mathrm{ml}) .0 .5 \mathrm{ml}$ of Folin-Ciocalteau reagent was added to $0.5 \mathrm{ml}$ of the extract solution and the total volume was adjusted to $8.5 \mathrm{ml}$ with distilled water. The tubes were kept at room temperature for 8 to10 min and thereafter $1.5 \mathrm{ml}$ of $20 \%$ sodium carbonate was added and kept for heating on water bath for $20 \mathrm{~min}$ at $40{ }^{\circ} \mathrm{C}$. The developed blue colour intensity was measured by recording the absorbance at $765 \mathrm{~nm}$ using a UV-visible spectrophotometer (Varian, CARY-300 Bio). Using distilled water the reagent blank was also prepared. The total phenolics in the extract were quantified by using a standard calibration curve. The gallic acid was used for preparation of standard. Phenolic extract contain total phenols in samples was expressed as gallic acid equivalent (GAE) milligrams per gram of the extract.

\section{Determination of crude fiber in extracts}

Keeping in mind that cellulose is the chief compound which represents fibers in plant matrix. Colorimetric determination of crude fibers in seed meal was carried out through following process (AOAC Official Method 984.04). $100 \mathrm{mg}$ of defatted seed meal treated with 1.25 per cent of sulphuric acid $\left(\mathrm{H}_{2} \mathrm{SO}_{4}\right)$ solution and kept at $100^{\circ} \mathrm{C}$ on water bath for 30 minutes then filtered and allow to cool at room temperature followed by washing with distilled water twice after that residual extract was treated with 1.25 per cent sodium hydroxide solution $(\mathrm{NaOH})$ and another time kept at $100^{\circ} \mathrm{C}$ on water bath for 30 minutes then filtered and allow to cool at room temperature followed by two time washing with distilled water kept for dry in hot air oven. After drying the sample $5 \mathrm{ml}$ of acidified potassium dichromate was added to it and kept on Luke warm water for 25-30 minutes till green color was appeared then filtered the solution and absorbance was recorded in UV-VIS spectrophotometer at wavelength $590 \mathrm{~nm}$.

\section{Determination of total glucosinolate in extracts}

An external standard method was used to determine total glucosinolate (Thies, 1982). The equation generated by linear regression after recording of absorbance from the UVVIS spectrophotometer were plotted against the known concentrations of stock solutions at 
varying concentrations was used to establish the concentrations for glucosinolate extracts. The following procedure was carried out. 200 mg of oven dried seed powder was taken in screw capped tube and poured with $300 \mu \mathrm{l}$ solvent mixture of 70 per cent methanol-water (MeOH: $\mathrm{H}_{2} \mathrm{O}$ ) and kept on water bath at $80{ }^{\circ} \mathrm{C}$ for 5 minutes and allow to room temperature then $2 \mathrm{ml}$ of distilled water was added and again repeated above heating procedure for 15 minutes then finally allowed to cool and centrifuge for 15 minutes at $1500 \mathrm{rpm}$. After that $30 \mu \mathrm{l}$ of supernatant drawn and $1800 \mu \mathrm{l}$ of tetrachloro palladium solution was dissolved in a test tube and kept in hot air oven at $70^{\circ} \mathrm{C}$ for 30 minutes. At last absorbance was recorded in UV-VIS spectrophotometer 405 nm.

\section{Determination of total flavonoids in extracts}

To determine the total flavonoid content in extract the aluminum chloride method was used (El Far et al., 2009). $500 \mu$ l of phenolic extract was dissolved in $1.5 \mathrm{ml}$ of ethanol and $100 \mu \mathrm{l}$ of 10 per cent Aluminium nitrate $\mathrm{Al}\left(\mathrm{NO}_{3}\right)_{3}$ or Aluminium chloride $\mathrm{AlCl}_{3}$ then $100 \mu \mathrm{l}$ of $1 \mathrm{M}$ Potassium acetate $\left(\mathrm{CH}_{3} \mathrm{COOK}\right)$ after that diluted with $2.8 \mathrm{ml}$ of distilled water and left over for cooling to room temperature for 40 minutes. At last optical density (O.D.) was measured at $415 \mathrm{~nm}$ in UV-VIS spectrophotometer.

Actually, Flavonoid-Aluminium complex was formed which developed yellow colour which is the measuring indices in flavonoids determination. Quercetin reagent was used as the standard for calibration for the flavonoids estimation. The concentration of flavonoid in the extract was calculated from the calibration plot and expressed as mg quercetin equivalent/gram of sample.

\section{Antioxidant assay}

The antioxidant activity of seed extract of $L$. stavium was determined by monitoring the 2,2-diphenyl-1-picrylhydrazyl

(DPPH) scavenging activity (Malabed et al., 2014). Varying amounts of methanolic seed extracts were placed in separate tubes. Different concentrations (equivalent to 200, 400, 600, 800 and $1000 \mathrm{ppm}$ ) of the extracts were taken in test tubes. The total volume was adjusted to $8.5 \mathrm{ml}$ by the addition of methanol. $5.0 \mathrm{ml}$ of $0.1 \mathrm{~m} M$ methanolic solution of DPPH was added to these tubes and mixed well with a vortex mixer. The tubes were kept at room temperature for $20 \mathrm{~min}$. The blank was prepared as above without the extract and methanol was used for the baseline correction. Changes in the absorbance of the extract samples were measured at $517 \mathrm{~nm}$ using the UV-visible spectrophotometer. Radical scavenging activity (RSA) was expressed as the inhibition percentage and was calculated using the following formula $\%$ Radical scavenging activity:

(Absorbance of blank-Absorbance of sample) $=X 100$

Absorbance of blank

\section{Calculation of $\mathrm{IC}_{50}$ concentration}

The concentration of extract corresponding to 50 percent inhibition $\left(\mathrm{IC}_{50}\right)$ was calculated with help of the curve of RSA percentage against concentration of extract. In triplications of concentrations each sample was assayed. Ascorbic acid was taken as standards.

\section{Estimation of sinapic acid content by HPLC}

HPLC system for chromatographic analysis consisted of a separation module (Waters $600 \mathrm{E}$ ) equipped with Empower software (Waters) and comprising of quaternary pump, an in-line vacuum degasser and a photodiode array detector (Waters 2996). The chromatographic separation was carried out in an isocratic elution mode on RP-18 column 
(250 X 4 mm, $5 \mu \mathrm{m}$ Merck, India). The mobile phase was a mixture of solvents: acetonitrile (40\%, solvent $\mathrm{A}$ ) and $0.1 \%$ acetic acid in water $(60 \%$, solvent $\mathrm{B})$. The solvent flow rate was $1.0 \mathrm{~mL} \min ^{-1}$ and the injection volume was $20 \mu \mathrm{L}$. Column temperature was $25^{\circ} \mathrm{C}$. The photo diode array detector wavelength was set at $272 \mathrm{~nm}$ for the identification and quantification of sinapic acid in extract of $L$. sativum. Chromatographic peak was identified on the basis of retention time. Concentration of sinapic acid in extract sample was calculated by comparing the integrated peak areas of the individual compound with that of a standard curve prepared from the corresponding standard.

\section{Results and Discussion}

\section{Mineral profiling}

For mineral profiling, different minerals had been analyzed in defatted seed extract of Lepidium sativum with help of Flame photometry and AAS. From Table 1, results showed the mineral content of $\mathrm{K}(11.9 \mathrm{~g} / \mathrm{kg})$, $\mathrm{Na}(1.23 \mathrm{~g} / \mathrm{kg}), \mathrm{Ca}(2.91 \mathrm{~g} / \mathrm{kg}), \mathrm{Mg}(3.15$ $\mathrm{g} / \mathrm{kg}), \mathrm{Zn}(0.045 \mathrm{~g} / \mathrm{kg}), \mathrm{Cu}(0.006 \mathrm{~g} / \mathrm{kg}), \mathrm{Fe}$ $(0.072 \mathrm{~g} / \mathrm{kg})$ and $\mathrm{Mn}(0.031 \mathrm{~g} / \mathrm{kg})$. Among analyzed minerals, potassium was found in higher concentrations compare to other minerals in seed extracts (Figure 1). Also zinc, copper, iron and manganese were found in lesser amounts. Mineral profiling of this plant showed that it is having very good source of potassium, iron and zinc which play may important role in growth and development of animal body.

\section{Phytochemical analysis}

\section{Extraction of oil and phenolics from seeds}

Seeds of Lepidium sativum were dried in shade and oil was extracted through soxhlet extraction method, after extraction yield was obtained around $25.3 \%$. Further, the phenolics content were extracted from seed extract remains after oil extraction through refluxing and obtained in $21 \%$ yield. In future study, seed oil can be analyzed for fatty acids profiling and other essential components in relevant to importance in animal feed.

\section{Estimation of total phenolics and flavonoids}

Total phenols and total flavonoids were found $8.53 \pm 0.0321$ and $3.89 \pm 0.081 \mathrm{mg} / \mathrm{g}$ of seed respectively (Table 2). Determination of total phenols calculations based on regression equation obtained from calibration curve of gallic acid used as standard. Similarly for determination of total flavonoids, calibration solutions were prepared in triplicate and analyzed (Table 3) as procedure described in methodology above. The one-way ANOVA calculated to compare the replicates of the calibration curve showed no significant difference between groups. The linear calibration curve was found in the range 0.5$30 \mu \mathrm{g} / \mathrm{mL}$ for quercetin dihydrate $\left(\mathrm{C}_{15} \mathrm{H}_{10} \mathrm{O}_{7}\right)$. The regression equation and correlation coefficient was found $(\mathrm{y}=0.0402 \mathrm{x}+0.0035)$ and 0.9985 respectively. It revealed a good linearity response for the method developed, and based on this all calculations was carried out to determine total flavonoids. Presence of phenol and flavonoids play a vital role in the prevention of cardiovascular illnesses, certain kinds of cancer, diabetes, brain dysfunction or other conditions associated with the aging process, a wide variety of pharmacological activities with so many potential health benefits.

\section{Estimation of crude fibres}

Crude fibers estimated by using linear regression calibration equation, $\mathrm{y}=0.016 \mathrm{x}$ +.018 and correlation coefficient $\mathrm{R}^{2}=0.9983$ that is obtained from cellulose which was used as standard. Value is presented in Table 2 around $23 \%$ of crude fibers which indicate it 
can be a very good source of dietary fibers in animal feeding.

\section{Antioxidant activity by DPPH technique}

Scavenging activity of DPPH radical per cent of L. sativum extracts at different concentrations are presented in Table 4. The methanol extracts of $L$. sativum exhibited
DPPH radical scavenging activity are $3.82 \%$, $29.30 \%, 61.78 \%, 85.30 \%$ and $94.27 \% 79.84$ at $6.25 \mathrm{ppm}, 12.5 \mathrm{ppm}, 25 \mathrm{ppm}, 50 \mathrm{ppm}$ and100 ppm respectively. With help of linear equation $\mathrm{y}=3.020 \mathrm{x}-12.42$ obtained by plotting a different concentrations of extracts and their scavenging activity on graph. The $\mathrm{IC}_{50}$ value of extract of $L$. sativum and ascorbic acid were found to be $21 \mathrm{ppm}$ and $9.3 \mathrm{ppm}$ respectively.

Table.1 Mineral contents in L. sativum seed extract

\begin{tabular}{|r|c|c|c|}
\hline S.N. & Minerals & Concentration & SD \\
\hline 1. & Potassium & $11.9 \mathrm{~g} / \mathrm{kg}$ & 0.03 \\
\hline 2. & Sodium & $1.23 \mathrm{~g} / \mathrm{kg}$ & 0.05 \\
\hline 3. & Calcium & $2.91 \mathrm{~g} / \mathrm{kg}$ & 0.09 \\
\hline $\mathbf{4 .}$ & Magnesium & $3.15 \mathrm{~g} / \mathrm{kg}$ & 0.11 \\
\hline $\mathbf{5 .}$ & Zinc & $0.045 \mathrm{~g} / \mathrm{kg}$ & 0.72 \\
\hline 6. & Copper & $0.006 \mathrm{~g} / \mathrm{kg}$ & 0.23 \\
\hline 7. & Iron & $0.072 \mathrm{~g} / \mathrm{kg}$ & 1.44 \\
\hline 8. & Manganese & $0.031 \mathrm{~g} / \mathrm{kg}$ & 1.27 \\
\hline
\end{tabular}

Values in the parenthesis ( \pm SD value), $n=3$

Table.2 Chemical composition of $L$. sativum seed meal

\begin{tabular}{|c|c|c|}
\hline S.N. & Chemical constituents & $\mathrm{mg} / \mathrm{g}$ seed \\
\hline $\mathbf{1 .}$ & Total phenols & $8.53 \pm .0321$ \\
\hline $\mathbf{2 .}$ & Total flavonoids & $3.89 \pm .081$ \\
\hline & & in per cent \\
\hline 3. & Crude fibers & $22.9 \pm 3.3$ \\
\hline & & $\boldsymbol{\mu m o l e s} / \mathbf{g}$ seed \\
\hline 4. & Glucosinolate & $89 \pm 1.6$ \\
\hline Note: ${ }^{\text {a }}$ Values represent the mean \pm S.D. $\mathrm{n}=3, \mathrm{a}=0.05$. \\
\hline
\end{tabular}

Table.3 Standard of Quercetin (standard) for calibration curve

\begin{tabular}{|c|c|c|}
\hline S.N. & Conc. $(\mu \mathrm{g} / \mathrm{ml})$ & Absorbance \\
\hline $\mathbf{1}$ & 5 & 0.20 \\
\hline $\mathbf{2}$ & 10 & 0.39 \\
\hline $\mathbf{3}$ & 15 & 0.62 \\
\hline $\mathbf{4}$ & 20 & 0.83 \\
\hline $\mathbf{5}$ & 25 & 1.01 \\
\hline $\mathbf{6}$ & 30 & 1.19 \\
\hline
\end{tabular}


Table.4 Inhibition percentage of Lepidium sativum (methanol extract) in DPPH assay

\begin{tabular}{|l|l|l|}
\hline Concentration (ppm) & Mean & Inhibition $(\%)$ \\
\hline Control & 0.16 & 0 \\
\hline 6.25 & 0.15 & 3.82 \\
\hline 12.5 & 0.12 & 29.30 \\
\hline 25 & 0.06 & 61.78 \\
\hline 50 & 0.03 & 85.30 \\
\hline 100 & 0.009 & 94.27 \\
\hline
\end{tabular}

Fig.1 Mineral content (g/Kg) of Lepidium seeds

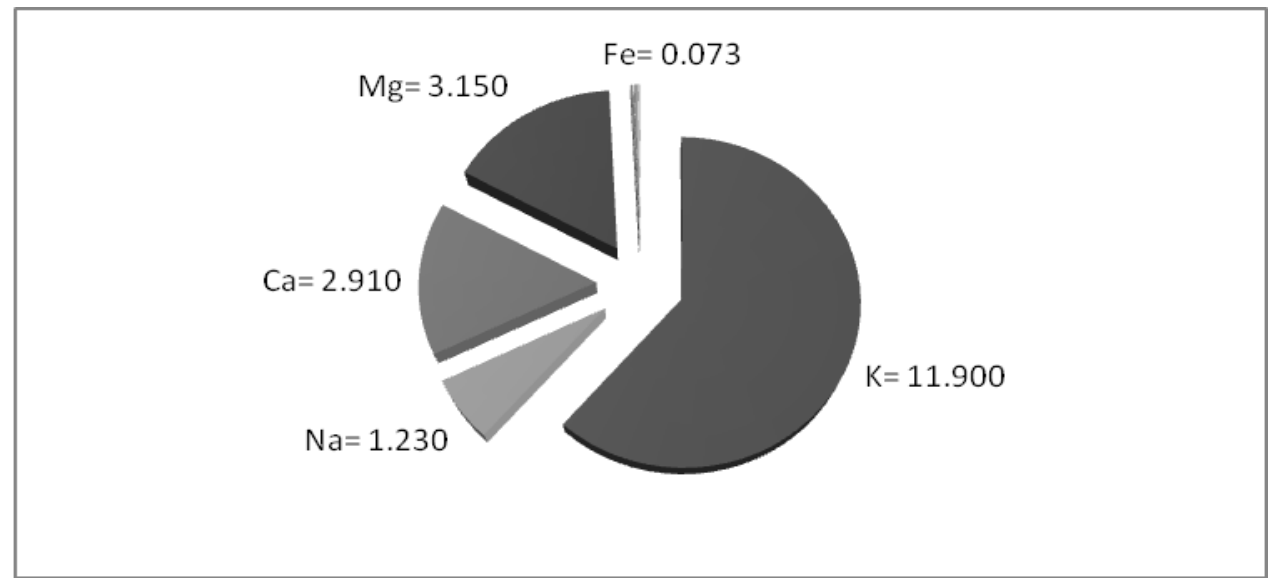

Fig.2 HPLC chromatogram of seed (Lepidium sativum)

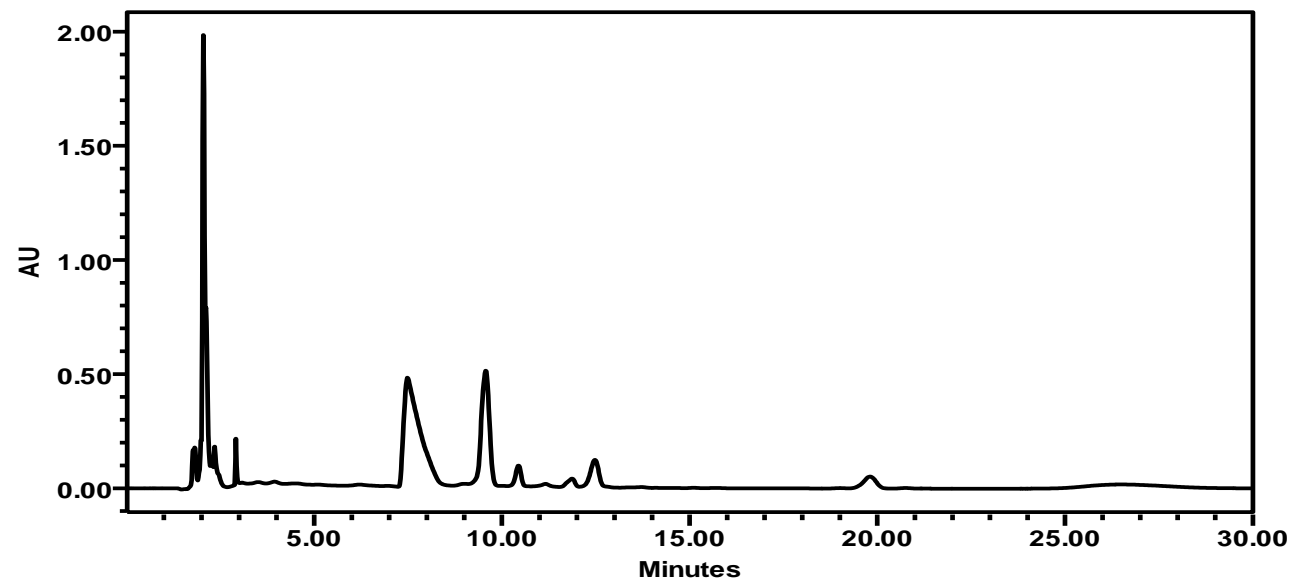

The above results clearly show significant DPPH radical scavenging activity of $L$. sativum with standard ascorbic acid therefore, L. sativum can be explore as herbal animal feed which is having good antioxidant potential that can help to reduce harmful oxidative process in ruminants.

Estimation of Sinapic acid content

Retention time for sinapic acid peak was recorded at 7.3 minute (Fig. 2). The photo 
diode array detector wavelength was set at $272 \mathrm{~nm}$ for the identification and quantification of sinapic acid in extract of $L$. sativum. Sinapic acid content was found to be $0.25 \%$.

In conclusion, from the present study it was revealed that $L$. sativum seeds have good mineral nutrients and other essential biochemical constituents in consideration as functional foods. It can be used further in nutraceuticals development because of its phenolic contents thus having antioxidant activity. In addition to functional foods this plant can contribute to herbal drugs for humans as well as animals. Finally, present study provides foundation for further study like bioavailability of minerals, effect on livestock health as well as the application of $L$. sativum in livestock feed because of its good lactation properties.

\section{Acknowledgments}

The authors thank the ICAR-Directorate of Medicinal and Aromatic Plants Research, Anand, Gujrat for providing facilities to carry out the research work. PK thanks ICARIndian Grassland and Fodder Research Institute, Jhansi, U.P. for given an opportunity to work at DMAPR and ICAR, New Delhi, for financial support.

\section{References}

Agarwal N and Sharma S. 2013. Appraisal of garden cress (Lepidium sativum L.) and product development as an all pervasive and nutrition worthy food stuff. Annals Food Sci. Technol., 14: $77-84$

Bauri RK, Tigga MN and Kullu SS. 2015. "A review on use of medicinal plants to control parasites. Indian J. Nat. Prod. Resour., 6: 268-277.
Bieler H G. 2010. Food is your best medicine. Ballantine Books.

Bnouham M. 2010. Medicinal plants with potential galactagogue activity used in the Moroccan pharmacopoeia. $J$. Complement. Integr. Med., 7: 1.

Diwakar BT, Dutta PK, Lokesh BR and Naidu KA. 2010. Physicochemical properties of garden cress (Lepidium sativum L.) seed oil. J. Am. Oil Chem. Soc., 87: 539-548.

El Far MM and Taie HA. 2009. Antioxidant activities, total anthocyanins, phenolics and flavonoids contents of some sweet potato genotypes under stress of different concentrations of sucrose and sorbitol. Aust. J. Basic \& Appl. Sci., 3: 3609-3616.

Gaur RD, Jyotsana S and R M Painuli. 2010. "Plants used in traditional healthcare of livestock by Gujjar community of Sub-Himalayan tracts, Uttarakhand, India. Indian J. Nat. Prod. Resour., 1: 243-248.

Gençcelep H, Uzun Y, Tunçtürk Y and Demirel K. 2009. Determination of mineral contents of wild-grown edible mushrooms. Food Chem., 113: 10331036.

Kirthikar KR. 1952. Lepidium sativum L. In: Indian Medicinal Plants, 1: 174-175.

Malabed RS, Marissa GN, Benjamin CA and Erika AFT. 2014. Characterization of the glucosinolates and isothiocyanates in mustard (Brassica juncea L.) extracts and determination of its myrosinase activity and antioxidant capacity. In: DLSU Research Congress.

Mirzaei F and Hari Venkatesh KR. 2012. Efficacy of phyto medicines as supplement in feeding practices on ruminant's performance: A review. Global J. Res. Med. Plants \& Indigen Med., 1: 391-403. 
Mirzaei-Aghsaghali A. 2012. Importance of medical herbs in animal feeding: A review." Ann. Biol. Res., 3: 918-923.

Patil PN. 2009. Herbal compositions improving lactation of farmed livestock U.S. Patent Application, 13/501, 574.

Sharma S and Agarwal N. 2011. Nourishing and healing prowess of garden cress (Lepidium sativum Linn.) A review. Indian J. Nat. Prod. Resour., 2: 292-297.

Singleton VL, Orthofer R and LamuelaRaventos RM. 1999. Analysis of total phenols and other oxidation substrates and antioxidants by means of folin- ciocalteu reagent. Methods Enzymol., 299: 152-178.

Thies W (1982). Complex-Formation between Glucosinolates and Tetra chloropalladate (II) and its Utilization in Plant Breeding. Fette Seifen Anstrichmittel, 84: 338-342.

Tipu MA, Akhtar MS, Anjum MI and Raja ML. 2006. New dimension of medicinal plants as animal feed. Pak. Vet. J., 26: 144-148.

Viegi L, Pieroni A, Guarrera PM and Vangelisti R. 2003. A review of plants used in folk veterinary medicine in Italy as basis for a databank. $J$. Ethnopharmacol., 89: 221-244.

\section{How to cite this article:}

Pushpendra Koli, Jitendra Kumar, Braj B. Singh and Satyanshu. Kumar. 2018. Mineral Profiling and Phytochemical Assessment of Lepidium sativum Seeds from Tropical Western India. Int.J.Curr.Microbiol.App.Sci. 7(08): 3720-3728.

doi: https://doi.org/10.20546/ijcmas.2018.708.377 